TI 2011-070/1

Tinbergen Institute Discussion Paper

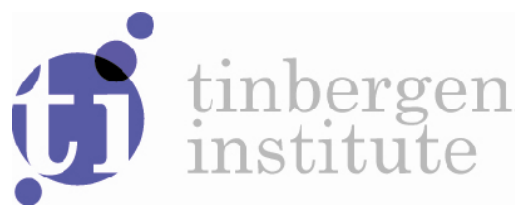

Bidding to give in the Field:

Door-to-Door Fundraisers had it right from the Start

Sander Onderstal

Arthur J.H.C. Schram

Adriaan R. Soetevent

Faculty of Economics and Business, University of Amsterdam, and Tinbergen Institute. 
Tinbergen Institute is the graduate school and research institute in economics of Erasmus University Rotterdam, the University of Amsterdam and VU University Amsterdam.

More TI discussion papers can be downloaded at http://www.tinbergen.nl

Tinbergen Institute has two locations:

Tinbergen Institute Amsterdam

Gustav Mahlerplein 117

1082 MS Amsterdam

The Netherlands

Tel.: +31(0)205251600

Tinbergen Institute Rotterdam

Burg. Oudlaan 50

3062 PA Rotterdam

The Netherlands

Tel.: +31(0)10 4088900

Fax: +31(0)104089031

Duisenberg school of finance is a collaboration of the Dutch financial sector and universities, with the ambition to support innovative research and offer top quality academic education in core areas of finance.

DSF research papers can be downloaded at: http://www.dsf.nl/

Duisenberg school of finance

Gustav Mahlerplein 117

1082 MS Amsterdam

The Netherlands

Tel.: +31(0)20 5258579 


\title{
Bidding to Give in the Field: \\ Door-to-Door Fundraisers Had it Right from the Start
}

\author{
Sander Onderstal, Arthur J.H.C. Schram, and Adriaan R. Soetevent \\ University of Amsterdam and Tinbergen Institute, The Netherlands
}

November 72011

\begin{abstract}
In a door-to-door fundraising field experiment, we study the impact of fundraising mechanisms on charitable giving. We approached about 4500 households, each participating in either an all-pay auction, a lottery, a non-anonymous voluntary contribution mechanism (VCM), or an anonymous VCM. In contrast to the VCMs, households competed for a prize in the all-pay auction and the lottery. Although the all-pay auction is the superior fundraising mechanism both in theory and in the laboratory, it raised the lowest revenue per household in the field. Our experiment reveals that this can be attributed to substantially lower participation in the all-pay auction than in the other mechanisms while the average donation for those who contribute is only slightly higher. We explore various explanations for this lower participation and favor one that argues that competition in the all-pay mechanism crowds out intrinsic motivations to contribute. Among the non-anonymous mechanisms, the lottery raises the largest revenue per household. Notably, the method that scored best, the anonymous VCM, is the one most used by door-to-door fundraisers in the Netherlands.
\end{abstract}

KEYWORDS: Charitable Fundraising; Field Experiment; Auction; Lottery; Voluntary Contribution Mechanism

JEL CODES: C93; D44; D64; H41

\section{ACKNOWLEDGMENTS}

The authors thank participants at the M-BEES 2010 conference in Maastricht, the ABEE 2010 symposium in Amsterdam, the ESA 2010 conference in Copenhagen, the Netspar workshop "Field Experiments and Research on Pensions, Aging, and Retirement" in Amsterdam, 2011, a Toulouse Behavioral and Experimental Economics Seminar (January, 2011), a seminar at Panthéon-Assas Paris II University (March, 2011), the IMEBE 2011 conference in Barcelona, the ESA 2011 world meeting in Chicago, the TIBER 2011 workshop in Tilburg, and the EARIE 2011 conference in Stockholm for useful suggestions. We are grateful to Jeffrey Carpenter, Stefano DellaVigna and David Reinstein for detailed comments on an earlier version of this paper. We are especially grateful to Roel van Veldhuizen for outstanding research assistance. Financial support from the University of Amsterdam Research Priority Area in Behavioral Economics is gratefully acknowledged. Please address correspondence to: Arthur Schram, CREED, Amsterdam School of Economics, Roetersstraat 11, 1018 WB Amsterdam, the Netherlands. Email: Schram@uva.nl. 


\section{INTRODUCTION}

Across the world, charities have raised staggering amounts of money in all kinds of funding drives. For example, Isaac and Schnier (2005) report estimates that over $\$ 240$ billion was raised by charities in the U.S. in 2003. By 2010, this had increased to over $\$ 290$ billion. ${ }^{1}$ Especially raffles and auctions seem to generate incredible amounts of money. An auction of a lunch with Warren Buffett (CEO of Berkshire Hathaway Inc.) raised \$2.6 million for a charity serving the homeless in San Francisco (Wall Street Journal, June 11, 2010). eBay has a special site for charity auctions that has by now raised approximately $\$ 190$ million. $^{2}$ But lotteries are also successful: the Dutch Postcode Lottery for example raised a total of more than $€ 500$ million in 2009 alone (which is almost $€ 30$ per inhabitant). ${ }^{3}$

This may make one think that lotteries or auctions are the best way to raise money for a charity. Other mechanisms are still widely used, however. For example, (anonymous) voluntary contribution mechanisms (VCM) are still very common in Dutch door-to-door fundraising and in church. This co-existence of mechanisms raises the question which yields the highest revenue. In previous work, we have addressed this question both theoretically (Goeree et al. 2005) and with laboratory experiments (Schram and Onderstal 2009). The experiments confirmed the theoretical prediction that all-pay auction raise more than lotteries. In this paper, we complement this project by comparing these mechanisms in a field experiment. Given the nature of the mechanisms actually used in the field, we also decided to extend the set studied by including VCMs.

Our comparison across mechanisms is in a private value environment, which is arguably the best description of the situation most observed when charities organize auctions or raffles (Schram and Onderstal 2009). In fact, this paper is the first to compare auctions, lotteries and VCMs in a private value environment. In this comparison, the main focus will be on the revenue mechanisms raise. This is what seems most relevant to most charities. Revenue may vary due to distinct participation levels or differences in contribution levels. We will address both issues.

For practical reasons (to be discussed below), we will restrict the mechanisms to the three types mentioned above and consider all-pay auctions (APA), lotteries (LOT) and (two variations of) the VCM. We will compare these mechanisms in an environment that is as familiar as possible to the participants in this field experiment. In fact, participants were unaware that they

\footnotetext{
${ }^{1}$ http://www.philanthropy.iupui.edu/news/2011/06/pr-GUSA.aspx.

${ }^{2} \mathrm{http}: / /$ givingworks.ebay.com/.

${ }^{3} \mathrm{http}$ ://files.postcodeloterij.nl/Jaarverslag_2009/magazine.html\#/spreadview/70/.
} 
were taking part in a comparative field experiment. They were told that the fundraising was "part of a research project by the University of Amsterdam on households' charitable giving" and given a phone number (of one of the authors) for more information. No participant requested such information. We enhanced the familiarity of the environment by keeping the logistics of the experiment very close to the way the charity concerned always conducts their (yearly) fund raising. In the Harrison and List (2004) taxonomy, our experiment lies somewhere between a 'framed field experiment' and a 'natural field experiment'.

When discussing previous studies comparing the mechanisms we are interested in, it is useful to organize them along two dimensions. First, we distinguish between theoretical studies, laboratory results and field experiments. Second we make a distinction between common value and private value environments. ${ }^{4}$ Since this is important for auctions in general, it should obviously be taken into account when studying charity auctions.

The theoretical results that the literature has shown for the mechanisms we study predict that VCM will be less successful than APA (Orzen, 2008; Corazzini et al., 2010) and LOT (Morgan, 2000; Lange et al., 2007; Orzen, 2008; Landry et al., 2006; Corazzini et al., 2010). Though this result has only been found in common value settings, it also holds true for the private values case as we will show in Section 3. The average theoretical contribution in APA is higher than in LOT in the case of both private (Goeree et al., 2005; Schram and Onderstal, 2009) and common values (Orzen, 2008; Faravelli, 2011; Corazzini et al., 2010).

In laboratory experiments, LOT raises more money than VCM (Morgan and Sefton, 2000; Lange et al., 2007; Orzen, 2008; Corazzini et al., 2010; all in common value settings). APA dominates VCM in terms of revenue in the lab when values are common (Orzen, 2008; Corazzini et al., 2010). The result that APA is a more successful fundraising mechanism than LOT has received mixed empirical support, however. Schram and Onderstal (2009) and Carpenter et al. (2011) confirm this result for private values, but in common value settings, LOT is found to raise at least as much money as APA (Orzen, 2008) or even to strictly outperform APA (Corazzini et al., 2010). By and large these results support the theoretical presumption that both LOT and APA

\footnotetext{
${ }^{4}$ In practice, most goods will combine common and private value characteristics (Goeree and Offerman 2002). For example, Eric Clapton's guitar legendary 1956 Fender Stratocaster 'Brownie' raised $\$ 497,500$ for the 'Crossroads Centre'. It seems clear that this guitar has different values to distinct people, but the resale value could create a common value element. Nevertheless, the extent to which values are affiliated is important. Private values seem more important for this guitar than for a pre-paid credit card, for example.
} 
will raise more than VCM in a laboratory experiment, though we are not aware of any direct laboratory comparison between VCM and either other mechanism in a private value setting.

There have also been a few mechanism comparisons in field experiments. ${ }^{5}$ For example, Landry et al., 2006 observe in a common value setting that LOT raises more money than VCM. Carpenter et al. (2008) study an environment best characterized as being a private value setting. They do not consider LOT and VCM as possible mechanisms, however. Instead, they compare APA to various other auction formats. They observe that revenue was lower in APA than in these alternatives and attribute this to lower participation in APA. These alternative mechanisms are irrelevant for our setting, however. This is because for door-to-door fundraising it does not make sense to consider other auction mechanisms than APA. ${ }^{6}$ These would require either returning money to those with lower than the highest bid, or first collecting bids (but not money) door-to-door and then returning at a later date to pick up money from the winner. Neither option would even be considered by the fundraisers we talked to. In a similar vein, two mechanisms that are very relevant options for door-to-door fundraising, VCM and LOT, are not considered by Carpenter et al. On the other hand, their application of APA to raise funds for a local school in a schoolyard event does provide an interesting opportunity to compare our results for this mechanism to those obtained in an entirely different context.

One should note an important difference between the two implementations of the APA, however. Carpenter et al. (2008) frame the APA as an auction by telling participants "[t]he person who places the highest bid will receive the item. However, this is an All-pay Auction which means that everyone must pay their bid whether or not they are the highest bidder. All the money we collect in the form of bids will be contributed directly to this preschool". Instead, in order to remain in sync with the VCM frame we chose to frame our APA (and also LOT) as a contribution by not using words like "pay" and "all-pay". To explain APA, we say "[we] will compare the contributions of all of these households. The household that contributed most will win ..."

\footnotetext{
${ }^{5}$ Other (field) experiments studying charitable giving do not compare mechanisms but focus on how contribution decisions are influenced by social comparison (Croson and Shang 2008; Frey and Meier 2004), social pressure (DellaVigna et al. 2010), status (Kumru and Vesterlund 2010) and seed money and sequential giving (Potters et al. 2005; Bracha et al. 2011).

${ }^{6}$ Carpenter et al. (2011) introduce a different frame for APA. In a laboratory experiment, participants pass around a bucket and may either contribute one token or withdraw. The bucket keeps going around until one participant remains. This basically makes it a second-price all-pay auction. The authors report that it outperforms other auction formats, both in contributions and in participation. Note that it would be very difficult to implement in door-to-door fundraising, however.
} 
where 'these households' refers to a group of 300 households competing for a single prize.

Finally, to the best of our knowledge there are no studies that attempt to compare fundraising mechanisms using naturally occurring field data.

Table 1 summarizes the state-of-the-art on fundraising mechanisms.

Table 1: State-of-the-Art

\begin{tabular}{lcc}
\hline & Common Value & Private Value \\
\hline Theory & APA $>$ LOT $>$ VCM & APA $>$ LOT $>$ VCM* \\
Laboratory Experiments & LOT $\geq$ APA $>$ VCM & APA $>$ LOT \\
Field Experiments & LOT $>$ VCM & $?$ \\
\hline $\begin{array}{l}\text { Note. Average revenue rankings are shown, based on the literature results described in the } \\
\text { previous paragraphs. }\end{array}$ \\
* LOT $>$ VCM is shown in Section 3 of this paper.
\end{tabular}

Aside from our contribution to theory (LOT $>$ VCM in the private value case), the table shows that ours is the first study to compare VCM to LOT and APA in a field experiment using a private value setting. This is an important endeavor for various reasons. First and foremost, the VCM is the mechanism most often used in door-to-door fundraising. In fact, the coordinating agency (the Central Bureau on Fundraising, CBF) lists all door-to-door drives by its members and this list contains only VCMs. ${ }^{7}$ Together, these raised almost $€ 40$ million in 2009 . In our experience, the only alternative mechanisms that fundraisers would seriously consider are LOT and APA. ${ }^{8}$ Second, voluntary contributions, lotteries and auctions seem to be the three categories of mechanisms typically used for fundraising, both in the Netherlands and elsewhere. Our field experiment allows us to compare these three categories. Third, the private value setting for the prize is likely to be the one most often encountered in charity auctions. Charities will generally not use cash or pre-paid credit cards (as in Landry et al. 2006) as prizes but instead items that have very different values to different people (like Eric Clapton's guitar). Finally, the fact that we were able to organize this in a natural setting is important. Not only does it mean that participants were making choices in a situation very familiar to them, it also means that it would be relatively easy to implement any of our mechanisms on a large scale. This is true because the fundraising that we organized in some neighborhoods of one town is held multiple times a year in the same way, all across the Netherlands.

\footnotetext{
${ }^{7}$ Charities that do not participate in the CBF do use other mechanisms in door-to-door fundraising, however. For example, the 'Grote Clubactie' organizes a yearly door-to-door lottery.

${ }^{8}$ Of course, our experience is mainly with Dutch charities. Given the practical problems related to other mechanisms, it is hard to conceive other door-to-door fundraisers thinking differently.
} 
The remainder of this paper is organized as follows. After presenting the experimental design in Section 2, we will discuss the theory and derive hypotheses in Section 3. The results are presented in Section 4 and further discussed in Section 5. Section 6 concludes.

\section{EXPERIMENTAL DESIGN}

The experiment was conducted in collaboration with the Dutch Brain Research Foundation (De Hersenstichting) on February 2 and 3, 2010, in selected districts in the Amsterdam suburb Amstelveen. ${ }^{9}$ The Dutch Brain Research Foundation received the gross revenues raised. All costs (including the expenses for buying the prizes, to be explained below) were covered by the University of Amsterdam's research funds.

We compare four treatments in a between-subjects design: two voluntary contribution mechanisms (VCMs), a lottery (LOT) and an all-pay auction (APA). In the week preceding the fundraiser, households received a flyer announcing the fundraising drive and explaining the procedure (and informing them that all costs were borne by the University of Amsterdam). ${ }^{10} \mathrm{~A}$ translation is presented in appendix A1. Respondents were requested to put their donation into a brown envelope attached to the flyer, to keep this near their front door and to drop it into the box when a solicitor came by in the following week. ${ }^{11}$ It is common practice in Dutch door-to-door fundraising that such envelopes are unmarked and individual contributions cannot be linked to household addresses. However, in order to award prizes in the lottery and all-pay treatments, the envelopes need to include the household's address. This severely reduces the anonymity of contributions, which may affect the amount contributed. ${ }^{12}$ To isolate the effect of (the lack of)

\footnotetext{
${ }^{9}$ This foundation (www.hersenstichting.nl) co-finances research on brain-related diseases, organizes media campaigns and develops brochures to increase the awareness and acceptance of brain diseases in Dutch society. In 2008, the fund received $€ 380.411$ in revenues from door-to-door fundraising, amounting to approximately $13 \%$ of its total income (€2.96 million). Door-to-door fundraising campaigns in the Netherlands are coordinated by the Central Bureau on Fundraising (CBF). This assigns to each charity a particular week to organize a nation-wide fundraising drive. This ensures that households are never approached by more than one charity a week and that charities can publicize their fundraising drive on national television and in newspapers. The Dutch Brain Research Foundation is assigned the first week of February (CBF, 2009).

${ }^{10}$ It is uncommon for Dutch fundraisers to announce a door-to-door drive via flyers. If the announcement has differential effects across treatments in the willingness to answer the door, this could compromise our results (cf. DellaVigna et al. 2010). We will return to this issue below.

${ }^{11}$ Supporting materials, pictures of the envelopes, boxes, flyers, solicitor scripts and itineraries etc. are available at the online appendix: http://tinyurl.com/biddingtogive.

${ }^{12}$ A priori, this effect may be positive or negative. If donators perceive social pressure to give generously, a lack of anonymity may induce higher contributions (e.g., Bohnet and Frey 1999; Andreoni and Petrie 2004; Rege and Telle 2004). On the other hand, there may be a 'moral norm' that contributions are a private matter and some people may give more in an anonymous setting (for an example, see Soetevent 2005, fn. 19). In addition, people may be wary
} 
anonymity, we implement two VCM treatments, one in which unmarked envelopes are used $\left(\mathrm{VCM}_{\mathrm{Ano}}\right)$ and one where the envelope (clearly) show the household's address $\left(\mathrm{VCM}_{\mathrm{Add}}\right)$. Note that $\mathrm{VCM}_{\mathrm{Ano}}$ enables the relevant comparison with APA and LOT from an external validity point of view, because it is the method currently most often used in door-to-door fundraising. Internal validity requires a comparison to $\mathrm{VCM}_{\text {Add, }}$, however, to enable an analysis of causes of possible differences between the VCM and APA or LOT.

In case a respondent would like to contribute when the solicitor arrives, but no longer has the original envelope, the solicitor provides a replacement envelope. The original and replacement envelopes are identical except for the fact that the latter has the address in italics.

The difference between the VCMs, the lottery and the all-pay auction is that a prize can be won in the latter two treatments. This was a 'Nintendo DS game console' with 'Dr. Kawashima's Brain Training Pack' (for sale online for €169). This prize was chosen after consultation with the Dutch Brain Research Foundation. They were keen on using a prize (Brain Training Pack) that could be seen as being connected to their activities. The prizes are awarded as follows:

LOT: A respondent receives a (virtual) lottery ticket for every euro she donates. In case of noninteger amounts, fractions of tickets are awarded. Household addresses are divided into groups of 300 each; one winner is selected per group. For an individual respondent, the chance of winning equals the ratio of her contribution to the sum of all contributions in her group of 300 addresses.

APA: Household addresses are divided into groups of 300. Per group, the respondent donating the highest amount wins the prize. In case of ties, the winner is determined randomly.

In both treatments, group selection is based on household addresses. Households without response as well as non-contributing households are included in the groups of 300. A short summary of the experimental design (including the numbers of addresses in the samples) is presented in Table $2 .^{13}$

that if they donate their name will be registered and they will be bothered for more donations. Another possibility is 'free rider anonymity'; people may be concerned that a small gift looks worse than nothing (Patel et al. 2010).

${ }^{13} 43$ observations were dropped because the information on the solicitor's record sheet was only readable for households that did donate; 19 observations were dropped because the donation could not be matched to a specific address. 
Table 2: Experimental design

\begin{tabular}{|c|c|c|c|c|}
\hline & \multicolumn{2}{|c|}{ Voluntary Contribution Mechanism } & Lottery & All-Pay Auction \\
\hline Treatment & $\left(\mathrm{VCM}_{\mathrm{Ano}}\right)$ & $\left(\mathrm{VCM}_{\text {Add }}\right)$ & (LOT) & (APA) \\
\hline Envelopes & No-Address & Address & Address & Address \\
\hline Prize & No & No & Nintendo & + Brain Training \\
\hline \# Addresses & 792 & 712 & 1483 & 1493 \\
\hline \# Households home & 494 & 454 & 988 & 962 \\
\hline \# Solicitors & 8 & 7 & 15 & 15 \\
\hline
\end{tabular}

Notes. For the treatments denoted in the second row, we show whether or not the donor's address was on the envelope (row 3 ), whether or not there was a prize (row 4), the numbers of addresses approached (row 5), households at home when the solicitor arrived (row 6) and the number of solicitors involved (row 7).

Various efforts were made to ensure that the sets of households per treatment were comparable.

Amstelveen consists of 21 'neighborhoods'. We selected three that are representative for the town on a series of characteristics such as income, fraction of single-parent households, fraction of non-Dutch inhabitants, etc. Details are available in part A of our online appendix. ${ }^{14}$ These neighborhoods comprise a total of 4542 addresses. We then defined 45 'routes' of more or less connected addresses (hence, an average route had about 100 addresses). Next, we carefully allocated routes to treatments. We did so alternating treatments as we 'walked' through a neighborhood. For example, we often had distinct treatments on one side of the street and the other and in one block and the next. Finally, as a final check for imbalance, we virtually walked each of these routes using Google Street View to distinguish between types of houses based on size, type (apartment, terrace house, semi-detached, detached), etc. With these precautions we hope to ensure that treatments are comparable in terms of household characteristics.

The 45 solicitors were randomly allocated to one route each and were therefore randomly allocated to treatments. In the week before the fundraising drive, all solicitors participated in a training session (one for each treatment in order to prevent cross-contamination and information exchange across treatments). These sessions lasted 50 to 60 minutes. Each session was led by the same researcher and included a presentation by the same spokesperson representing the charity. Solicitors received information on the charity and were instructed how to approach respondents. They had to practice approaching people to solicit donations. For this, they used a script (see the online appendix) while facing a professional actor playing the role of respondent. Solicitors approached each household on their route exactly once. All solicitors went out to solicit

\footnotetext{
${ }^{14}$ Unfortunately, such background information is only available at the neighborhood level. Therefore, we cannot use this information to control for differences at the household level. The only information we have at that level is gathered by the solicitors (see below).
} 
contributions in the evening (18-21 o'clock) of February $2^{\text {nd }}$. Those who had not finished their route continued in the evening of February $3^{\text {rd }} .15$

Solicitors were recruited among the students of the University of Amsterdam. They were paid a lump-sum $€ 150$ after the data of their route had been handed in and processed. Solicitors participated in a ten-minute intake interview in which they were asked for some background characteristics, such as age, gender, height and weight, and experience with (door-to-door) fundraising. They also filled out a survey in which they reported the extent to which they agreed with twenty statements on a five-point Likert scale (from strongly agree to strongly disagree). This survey contained ten statements, each in a positive and a negative frame. The statements used (e.g., "I feel I do not have much to be proud of") date back to Rosenberg (1965) and are used to compose measures of assertiveness, sociability, self-efficacy, performance motivation and self-confidence. Responses are scaled such that for each of these personality traits an individual measure in the range $\{-8,-7, \ldots, 8\}$ is obtained. ${ }^{16}$

Finally, to obtain a measure of a solicitor's physical attractiveness, digital photographs of each solicitor were taken. Independent evaluators were invited to rate a random batch of 15 photos on a scale from (1) "lacking in physical beauty or proportion, extremely unattractive" to (10) "strikingly handsome or model beautiful". To guarantee a strict separation between solicitors and raters, the raters were recruited from the CentERlab subject pool, the facility for experiments at Tilburg University. Selected students in this subject pool were invited by email to participate in an online experiment in which they had to score 15 different individuals on their physical attractiveness. A total of 175 evaluators completed the task, leading to a total of 2625 personal attractiveness rankings. As an incentive for evaluators to complete the ranking, one randomly selected evaluator was awarded a prize of $€ 500$. For our analysis, each rater's scores were normalized to arrive at a standardized scale across raters. ${ }^{17}$

Table 3 shows summary statistics of the solicitor characteristics by treatment. None of the average solicitor characteristics is different across treatments at the $p=0.05$ level, implying that the random assignment of solicitors to treatments was successful. Approximately half of the

\footnotetext{
${ }^{15}$ For the different treatments, the fraction of routes completed at February $3^{\text {rd }}$ are $0.33\left(\mathrm{VCM}_{\text {Ano }}\right), 0.30\left(\mathrm{VCM}_{\mathrm{Add}}\right)$, 0.41 (LOT) and 0.15 (APA), respectively. Correcting for the day of collection does not change any of the results presented below.

${ }^{16}$ The same procedure has been used in other door-to-door fundraising experiments to assess solicitors' personality traits, e.g. see Landry et al. (2006) and Soetevent (2011).

${ }^{17}$ See Landry et al. (2006) for details about this standardization procedure..
} 
solicitors are male and the average solicitor age is just below 22 years. The score for the personality traits measures are similar to those in Soetevent (2011).

Table 3: Summary statistics solicitor characteristics

\begin{tabular}{lcccc}
\hline & $\begin{array}{c}\text { VCM } \\
\text { Anonymous }\end{array}$ & $\begin{array}{c}\text { VCM } \\
\text { Address }\end{array}$ & Lottery & All-Pay \\
\hline Total \# of solicitors & 8 & 7 & 15 & 15 \\
& & & & 0.533 \\
& 0.500 & 0.571 & 0.467 & $(0.133)$ \\
\hline Fraction male solicitors & $(0.189)$ & $(0.202)$ & $(0.133)$ & 21.733 \\
& 21.375 & 22.000 & 22.000 & $(0.589)$ \\
\hline Average age & $(0.680)$ & $(1.069)$ & $(0.577)$ & 4.867 \\
& 4.500 & 3.429 & 4.000 & $(0.435)$ \\
\hline Mean sociability & $(1.069)$ & $(0.948)$ & $(0.609)$ & 4.533 \\
& 4.000 & 3.000 & 4.133 & $(0.350)$ \\
\hline Mean assertiveness & $(1.210)$ & $(1.574)$ & $(0.515)$ & 3.533 \\
& 4.125 & 4.571 & 4.733 & $(0.363)$ \\
\hline Mean performance & $(0.549)$ & $(0.369)$ & $(0.530)$ & 1.133 \\
Motivation & 1.750 & 1.857 & 2.133 & $(0.616)$ \\
\hline Mean self-confidence & $(0.648)$ & $(0.738)$ & $(0.696)$ & 3.600 \\
& 4.875 & 3.143 & 3.733 & $(0.486)$ \\
\hline Mean BMI & $(0.295)$ & $(0.911)$ & $(0.530)$ & 22.178 \\
& 22.990 & 21.533 & 21.755 & $(0.649)$ \\
\hline Mean beauty rating & $(0.996)$ & $(0.464)$ & $(0.483)$ & 0.245 \\
& -0.139 & -0.162 & -0.066 & $(0.169)$ \\
\hline
\end{tabular}

Notes. Cells give mean solicitor values for (depicted in the first column) per treatment (given in the first row). Standard errors in parentheses. None of the variables are statistically significant at the $5 \%$-level across treatments.

\section{THEORY AND HYPOTHESES}

The hypotheses that we will test in our field experiment are derived by extending the theory on private value charity auctions that we presented in Goeree et al. (2005) and Schram and Onderstal (2009). ${ }^{18}$ Suppose there are $n$ potential donors, labeled $i=1,2, \ldots, n$. A charitable organization may award a prize to one of the donors. Donor $i$ assigns (private) value $v_{i} \geq 0$ to the prize, where the $v_{i}$ 's are i.i.d. drawn from the same differentiable distribution function $F$ on the interval $\left[0, v_{\max }\right]$, with $v_{\max }>0$ and $F^{\prime}(v)>0$ for all $v \in\left[0, v_{\max }\right)$. We assume that the 'marginal

\footnotetext{
${ }^{18}$ In Section 5, we will discuss the implications of relaxing several of the assumptions we make here.
} 
revenue' $M R(v)=v-[1-F(v)] / F^{\prime}(v)$ is strictly increasing in $v$ for all $v \in\left[0, v_{\max }\right) .{ }^{19}$ We allow for the case $F(0)>0$, i.e., a strictly positive mass of donor types may assign value zero to the prize.

Donor $i$ 's utility ${ }^{20}$ is separable in wealth and benefit from donations and is given by:

$$
U_{i}=u_{i}\left(w_{i}+v_{i} I_{i}-d_{i}\right)+\omega_{i}\left(d_{i}\right)+\delta_{i}\left(D_{-i}\right)
$$

where $w_{i}$ stands for $i$ 's initial wealth, $d_{i}$ is $i$ 's donation, $D_{-i}$ is the donations by others and $I_{i}=1\left[I_{i}\right.$ $=0$ ] if donor $i$ wins [does not win] the prize. The function $u_{i}$ measures utility from wealth and is differentiable, strictly increasing, and concave. $\omega_{i}$ gives the benefit $i$ derives from the own donation to the charitable organization (which may include feelings of warm glow as in Andreoni, 1995) and is differentiable, increasing, and concave. We normalize by setting, $u_{i}(0)=$ $\omega_{i}(0)=0$. Finally, the function $\delta_{i}$ measures $i$ 's benefit from others' donations, with $\delta_{i}(0)=0$.

Proposition 1 shows that the equilibrium contribution level is higher in an all-pay auction and a lottery than in a voluntary contribution mechanism. The proof is in Appendix A2.

PROPOSITION 1. Individual contribution levels in APA and LOT exceed those in both versions of the VCM.

The intuition underlying this proposition is as follows. In the VCMs, the respondent has no chance for a prize and her donation therefore cannot affect the probability of winning a prize. The optimal contribution is determined by the relationship between the marginal effects of donation on reduced utility from wealth and increased utility from the benefit of donating. Exactly the same tradeoff is faced when a prize can be won. Now, however, donations also positively affect the probability of winning a prize and therefore the optimal donation will be higher.

\footnotetext{
${ }^{19}$ Marginal revenue refers to the equilibrium contribution of a donor with value $v$ to the charity's revenue conditional on winning. The assumption that the marginal revenue is increasing is satisfied for many familiar distributions, including the uniform distribution and the normal distribution.

${ }^{20}$ For a discussion of ways to model preferences for charity giving, see Isaac et al. (2010) or Isaac and Salmon (2006).
} 
In order to compare the equilibrium properties of APA and LOT, we assume risk neutrality, i.e., $u(x)=x$, and proportional benefits from the own donation, i.e., $\omega_{i}(d)=\alpha d, \alpha \in[0,1)$. In that case, an all-pay auction raises more revenue in equilibrium than a lottery does.

PROPOSITION 2. If donors are risk neutral and bidders obtain proportional benefits from their own donation, APA raises more money than LOT.

Goeree et al. (2005) provide a formal proof of Proposition 2. The intuition underlying it is as follows. In the standard symmetric independent private values model in which $\omega_{i}\left(d_{i}\right)=0$, Myerson's (1981) revenue equivalence result shows that, given that the charity never keeps the prize, it maximizes its revenue if it always allocates the prize to the donor with the highest marginal revenue. In the equilibrium for APA, the donor with the highest value always wins the prize, which by assumption is also the donor with the highest marginal revenue. Therefore, the APA implements the revenue maximizing mechanism conditional on the charity always rewarding a prize. In the equilibrium of LOT, the donor with the highest value wins with probability strictly below one. Therefore, LOT is suboptimal and a fortiori, raises less money than APA. In the case of proportional benefits from the own donation, in both APA and LOT, donors behavior is equivalent to a situation where they do not care about charity and only pay a fraction $(1-\alpha)$ of their donation. The proposition follows because their equilibrium donations are equal to the equilibrium donations in the standard model inflated by a factor $(1-\alpha)^{-1}$.

Finally, we consider the extensive margin, i.e., households' decisions whether or not to participate in the event by donating. Participating is equivalent to a non-zero contribution. From Proposition 1, it immediately follows that at least as many donors will participate in APA and LOT as in VCM. Note that we assume that a donor's willingness to contribute to the charity does not depend on others' contributions. Therefore, donors who value the prize at zero have the same incentives to donate in all mechanisms. Moreover, under the restrictions of risk neutrality and proportional benefits from the donor's own donation, Goeree et al. (2005) and Schram and Onderstal (2009) show that all donors with a strictly positive value for the prize contribute a strictly positive amount in equilibrium in both APA and LOT. So, in either mechanism, only those donors who assign value zero to the prize may not participate. 
PROPOSITION 3. Donors are less likely to donate a strictly positive amount in both versions of the VCM than in APA and LOT. In APA and LOT, if donors are risk neutral and bidders obtain proportional benefits from their own donation, zero contributions are equally likely.

The above propositions yield the following testable hypotheses.

HyPOTHESIS 1 (H1: AVERAGE DONATION). In terms of average individual donations, the fundraising mechanisms are ranked

$$
\mathrm{APA}>\mathrm{LOT}>\mathrm{VCM}_{\text {Ano }} \sim \mathrm{VCM}_{\text {Add }}
$$

HYPOTHESIS 2 (H2: PARTICIPATION). With respect to household participation, the fundraising mechanisms are ranked

$$
\mathrm{APA} \sim \mathrm{LOT}>\mathrm{VCM}_{\text {Ano }} \sim \mathrm{VCM}_{\text {Add }}
$$

In Schram and Onderstal (2009) we used data collected in laboratory experiments to test the hypotheses with respect to the APA-LOT comparison. Contributions were significantly higher in the all-pay case in support of H1. In contrast to H2, however, we observed that participation was significantly lower in the all-pay auction than in the lottery. One thing we will do here is to check whether these conclusions are robust and carry over to the field setting.

\section{EXPERIMENTAL RESULTS}

To start, Table 4 gives summary statistics on contributions and respondents' background in each treatment. Before turning to the results on revenue and participation, let us discuss the extent to which households were assigned to treatments in a representative way. First of all, note that there is some evidence that the distribution of the respondents' age (as estimated by the solicitors) differs across treatments. In particular, respondents seem to be relatively young in $\mathrm{VCM}_{\text {Ano, }}$, compared to the other treatments. This is mainly due to a relatively high representation of respondents younger than 30 years old. We do not attribute this to poor randomization across treatments, however. Given that the respondent's age is estimated by the solicitor and the fact that randomization seems fine for the more objectively measurable characteristics like gender composition and the fraction of (semi)detached houses, we tend to conclude that that it is caused 
Table 4: Summary statistics respondents (standard errors within parentheses)

\begin{tabular}{|c|c|c|c|c|}
\hline & $\begin{array}{c}\text { VCM } \\
\text { Anonymous }\end{array}$ & $\begin{array}{c}\text { VCM } \\
\text { Address }\end{array}$ & Lottery & All-Pay \\
\hline \multirow{2}{*}{$\begin{array}{l}\text { average donation per household (in } € \text { ) } \\
\text { that answered the door }\end{array}$} & 2.006 & 1.796 & 1.858 & $1.649 * *$ \\
\hline & $(0.148)$ & $(0.092)$ & $(0.072)$ & $(0.074)$ \\
\hline \multirow[t]{2}{*}{ fraction households donating } & 0.676 & 0.667 & 0.635 & $0.546^{* * *}$ \\
\hline & $(0.021)$ & $(0.022)$ & $(0.015)$ & $(0.016)$ \\
\hline \multirow{2}{*}{$\begin{array}{l}\text { contribution (in } € \text { ) conditional on } \\
\text { donating }\end{array}$} & 3.037 & 2.715 & 2.917 & 3.068 \\
\hline & $(0.203)$ & $(0.106)$ & $(0.088)$ & $(0.103)$ \\
\hline \multirow{2}{*}{$\begin{array}{l}\text { contribution (in } € \text { ) conditional on } \\
\text { donating and original envelope }\end{array}$} & --- & 2.867 & 3.095 & 3.166 \\
\hline & $(---)$ & $(0.128)$ & $(0.125)$ & $(0.162)$ \\
\hline \multirow{2}{*}{$\begin{array}{l}\text { contribution (in } € \text { ) conditional on } \\
\text { donating and replacement envelope }\end{array}$} & --- & 2.503 & 2.700 & 3.011 \\
\hline & $(---)$ & $(0.185)$ & $(0.123)$ & $(0.135)$ \\
\hline \multirow[t]{2}{*}{ fraction females } & 0.524 & 0.544 & 0.543 & 0.537 \\
\hline & $(0.022)$ & $(0.023)$ & $(0.016)$ & $(0.016)$ \\
\hline \multirow[t]{2}{*}{ average age $^{1}$} & 43.004 & 44.451 & $46.356 * * *$ & $44.757 * *$ \\
\hline & $(0.637)$ & $(0.648)$ & $(0.476)$ & $(0.407)$ \\
\hline \multirow[t]{2}{*}{ fraction aged $<30$} & 0.194 & 0.145 & $0.117 * * *$ & $0.132 * * *$ \\
\hline & $(0.018)$ & $(0.017)$ & $(0.010)$ & $(0.011)$ \\
\hline \multirow[t]{2}{*}{ fraction aged $30-45$} & 0.421 & 0.445 & 0.433 & 0.421 \\
\hline & $(0.022)$ & $(0.023)$ & $(0.016)$ & $(0.016)$ \\
\hline \multirow[t]{2}{*}{ fraction aged 45-60 } & 0.247 & 0.271 & 0.269 & $0.335 * * *$ \\
\hline & $(0.019)$ & $(0.021)$ & $(0.014)$ & $(0.015)$ \\
\hline \multirow[t]{2}{*}{ fraction aged $>60$} & 0.138 & 0.139 & 0.180 & 0.112 \\
\hline & $(0.016)$ & $(0.016)$ & $(0.012)$ & $(0.010)$ \\
\hline \multirow[t]{2}{*}{ fraction (semi)detached } & 0.081 & 0.101 & 0.082 & 0.098 \\
\hline & $(0.012)$ & $(0.014)$ & $(0.009)$ & $(0.010)$ \\
\hline total households approached & 792 & 712 & 1483 & 1493 \\
\hline total households home \& no response & 7 & 0 & 10 & 10 \\
\hline total households home \& response & 494 & 454 & 988 & 962 \\
\hline fraction of households home & 0.63 & 0.64 & 0.67 & 0.65 \\
\hline \# using original envelope ${ }^{2}$ & -- & $179(39.4 \%)$ & $329(33.3 \%)$ & $250(26.0 \%)$ \\
\hline \# using replacement envelope ${ }^{2}$ & -- & $118(26.0 \%)$ & $290(29.4 \%)$ & $259(26.9 \%)$ \\
\hline
\end{tabular}

Notes. Mean values of the variables denoted in the first column are given per treatment (given in the first row). Standard errors are in parentheses. $* *(* * *)$ indicate statistically significant differences from $\mathrm{VCM}_{\mathrm{Ann}}$ at the $5 \%$-level $(1 \%$-level). Sample sizes vary across rows of the table due to missing values.

${ }^{1}$ Age as estimated by the solicitors.

${ }^{2}$ Percentage within parentheses is percentage of households home using given type of envelope. The percentages do not exactly add to the total percentage of households home that donate because in each treatment, a small fraction of envelopes $\left(\mathrm{VCM}_{\mathrm{Add}}\right.$ $1.3 \%$; Lottery $0.8 \%$; AllPay $1.7 \%$ ) could not be classified with certainty as either "original" or "replacement".

either by natural statistical variation or by some solicitors consistently under- or overestimating their respondents' ages. ${ }^{21}$ Naturally, we will correct for estimated age in the statistical analyses to be presented. Finally, the fraction of households who opened the door when the solicitor dropped by ('home') is somewhat larger in the LOT treatment (0.67) than in the anonymous VCM $(0.63)$. Though statistically significant $(N=2275, p=0.043)$ the difference is small. ${ }^{22}$ Our analyses will be

${ }^{21}$ This conclusion is supported by regressions of estimated age on treatment dummies and of estimated age on solicitor dummies. These provide evidence of such a structural bias at the solicitor level and as a result at the treatment level as well. More details are available upon request.

${ }^{22}$ Unless stated otherwise, the $p$-values reported in this section are based on two-tailed $t$-tests. 
based on households that opened the door. ${ }^{23}$ Therefore, this difference would only affect our results if being home and opening the door is somehow correlated with the variables we use to explain donations. Given our randomization procedure we do not expect such correlations. This expectation is confirmed by additional regressions (cf. footnote 21 ).

We now focus on the two measures of a mechanism's 'success': the average revenue per household and the fraction of households that 'participate' by contributing a positive amount, both conditional on opening the door when the solicitor rang. In average household donations, the fundraising mechanisms are ranked $\mathrm{VCM}_{\text {Ano }}>$ LOT $>\mathrm{VCM}_{\text {Add }}>$ APA. A Kruskal-Wallis test rejects the null hypothesis that the observations of the different treatments are drawn from the same distribution $(p<0.001)$. Testing pair-wise differences, the VCM treatment with unmarked envelopes generates revenues of $€ 2.01$ per household that opens the door while the APA raises on average only $€ 1.65$. This difference is significant with $p=0.012$. The only other significant difference is between revenues in APA and LOT, the latter are $€ 1.86$ and also higher than those in APA $(p=0.046){ }^{24,25}$ Aside from the mean, the distribution of amounts given may differ across treatments. Figure 1 shows a histogram of amounts donated per treatment. The equality of distributions is rejected only for APA versus any of the other treatments $(p<0.001$, Kolmogorov-Smirnov tests). It appears that contributions up to $€ 2.00$ are more likely for the VCMs than for APA but the differences become small for higher contribution levels.

Next, consider household participation. Here we find a similar result: whereas about 65 percent of the respondents who open the door participate in $\mathrm{VCM}_{\mathrm{Ano}}, \mathrm{VCM}_{\mathrm{Add}}$ and LOT, this number decreases to 55 percent in APA $(p<0.01$ for all pairwise comparisons between APA and

\footnotetext{
${ }^{23}$ Of course, it may have happened that people realized it must be the solicitor and therefore did not open the door. This is unlikely, however, because the flyer did not specify a date and time at which the solicitor would drop by, only that it would be "between February 1 and 6" (cf. appendix A.1). Because the fundraiser took place during a winter evening, solicitors could tell whether someone was home because the lights inside would be burning. Solicitors reported if this occurred and it happened only 27 times (less than 1 percent of the households who were home). Whenever this occurred, it seems treatment independent: see table 4. In our analysis, we classified these 27 households as 'not home' because no contact with the solicitor was established. Part B of the online appendix shows that the estimates to be presented below are unaffected if these households are coded as 'home'. In six cases, respondents talked with the solicitor through an intercom; these households were classified as 'home'. Finally, because the flyer did not specify a date, it is extremely unlikely that respondents avoided being home at all. Nevertheless, for completeness' sake, results for the full sample of all addresses, including households not home, can be found in part $\mathrm{C}$ of the online appendix. These regressions confirm the main conclusions of this paper.

${ }^{24}$ Non-parametric Mann-Whitney tests at the solicitor level of the difference in amount given between $\mathrm{VCM}_{\text {Ano }}$ and APA and between LOT and APA give $p$-values of 0.121 and 0.152 , respectively.

${ }^{25}$ Both VCMs significantly outperform APA and LOT if the cost of the prize (about $€ 0.85$ per household that opened the door) is taken into account. This strengthens our conclusion that Dutch fundraisers had it right from the start by predominantly using the anonymous VCM.
} 
any of the other treatments; of the remaining pairwise comparisons none is close to significance). ${ }^{26}$ The distinct participation level of APA is strong enough to render the simultaneous test statistically significant: the null hypothesis of equality of the distribution of participation decisions across treatments is rejected by the Kruskal-Wallis test with $p<0.001$. Finally, the only significant pair-wise difference in conditional contributions is between $\mathrm{VCM}_{\mathrm{Add}}$

Figure 1: Amounts donated

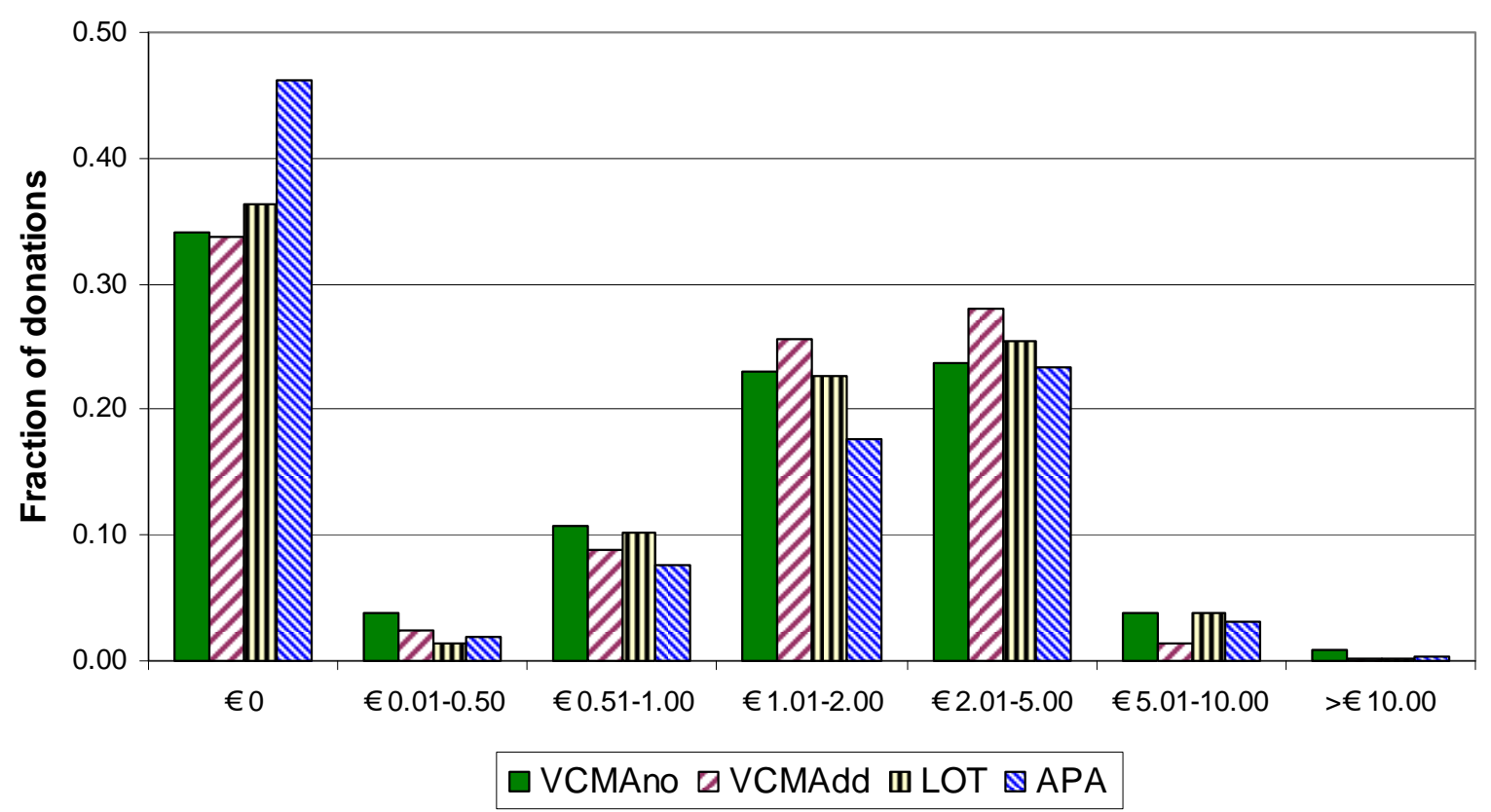

Notes. Bars show the fraction of donations within the sets denoted on the horizontal axis.

(average of €2.71) and APA (€3.07) with $p=0.025 .^{27}$ A loose way to summarize these results is that respondents in APA participate less often than in other treatments. When they do participate, they contribute more. This is not enough to compensate for lower participation, however. ${ }^{28}$

\footnotetext{
${ }^{26}$ The Mann-Whitney test statistic gives similar results: for pairwise comparisons between APA and any of the other treatments $\left(\mathrm{VCM}_{\mathrm{Add}}\right.$, LOT, APA) gives $p=0.033,0.032,0.032$, respectively while none of the remaining comparisons is close to significance.

${ }^{27}$ The Mann-Whitney does not identify significant differences for any of the pair-wise comparisons.

${ }^{28}$ In part D of the online appendix, we show that these differences across treatments cannot be attributed to the allocation of solicitors.
} 
To better understand this variation in contributions and participation, we perform a regression analysis that allows us to control for a number of covariates that potentially affect these decisions. First we estimate a linear regression model of the amount donated by a respondent (including zeros) on treatment dummies and a set of other explanatory variables to be described below:

$$
L_{i j}=Z_{i j} \theta+X_{i j} \beta+\varepsilon_{i j}
$$

In this equation, $L_{i j}$ is the household $j$ 's contribution to solicitor $i$ (conditional on being home); $Z$ is a vector of treatment dummies and $X$ is a vector of observable solicitor and respondent characteristics. More specifically, $Z$ consists of three dummy variables, which distinguish between the addressed VCM, the lottery and the all-pay auction. The unmarked VCM treatment is included in the constant term. $\theta$ and $\beta$ are coefficients to be estimated and $\varepsilon$ is a white noise disturbance. We also estimated a tobit model, because contributions are restricted to be nonnegative. The results are presented in part $\mathrm{E}$ of the online appendix. They show no substantial differences with the results presented here.

$X$ includes three dummy variables categorizing the respondent's estimated age, as well as his or her gender and a dummy indicating whether or not the respondent's house is (semi-)detached (as opposed to being a terraced house). $X$ also includes dummy variable describing the solicitor's gender and a series of personality traits as well as her or his BMI-index and beauty rating. Finally, we also add fixed effects for the neighborhood the respondent lives in. Table 5 presents estimates for different specifications of this model.

Second, we estimate a probit model. A latent varable $\left(C^{*}{ }_{i j}\right)$ is related as follows to the observed participation decision $C_{i j}$ :

$$
\left\{\begin{array}{c}
C_{i j}^{*}=Z_{i j} \gamma+X_{i j} \alpha+\varepsilon_{i j} \\
C_{i j}=1 \quad \text { if } C_{i j}^{*}>0 \\
C_{i j}=0 \quad \text { if } C_{i j}^{*} \leq 0
\end{array}\right.
$$

$C_{i j}$ equals one if solicitor $i$ receives a positive contribution from household $j$ and zero otherwise. The explanatory variables are identical to those in equation (1). Here, $\gamma$ and $\alpha$ are the 
Table 5 : OLS regressions: Household contributions

\begin{tabular}{|c|c|c|c|c|}
\hline Dependent variable & $\begin{array}{c}(1) \\
\text { amount }\end{array}$ & $\begin{array}{c}(2) \\
\text { amount }\end{array}$ & $\begin{array}{c}(3) \\
\text { amount }\end{array}$ & $\begin{array}{c}\text { (4) } \\
\text { amount }\end{array}$ \\
\hline & \multicolumn{4}{|c|}{ Treatment } \\
\hline \multirow[t]{2}{*}{$\mathrm{VCM}_{\text {Add }}$} & -0.194 & -0.193 & -0.222 & -0.254 \\
\hline & $(0.184)$ & $(0.153)$ & $(0.149)$ & $(0.165)$ \\
\hline \multirow[t]{2}{*}{ Lottery (LOT) } & -0.135 & -0.111 & -0.139 & -0.161 \\
\hline & $(0.171)$ & $(0.145)$ & $(0.140)$ & $(0.147)$ \\
\hline \multirow[t]{2}{*}{ AllPay (APA) } & $-0.355^{*}$ & $-0.323 *$ & $-0.352 * *$ & $-0.425^{* *}$ \\
\hline & $(0.203)$ & $(0.182)$ & $(0.174)$ & $(0.167)$ \\
\hline \multicolumn{5}{|c|}{ Respondent Characteristics } \\
\hline \multirow[t]{2}{*}{ aged $<30$} & & & $-0.414 * * *$ & $-0.421 * * *$ \\
\hline & & & $(0.099)$ & $(0.097)$ \\
\hline \multirow[t]{2}{*}{ aged $45-60$} & & & -0.068 & -0.0670 \\
\hline & & & $(0.106)$ & $(0.108)$ \\
\hline \multirow[t]{2}{*}{ aged $>60$} & & & -0.175 & -0.185 \\
\hline & & & $(0.124)$ & $(0.123)$ \\
\hline \multirow[t]{2}{*}{ female respondent } & & & $0.256^{* *}$ & $0.257 * * *$ \\
\hline & & & $(0.097)$ & $(0.095)$ \\
\hline \multirow[t]{2}{*}{ semidetached } & & & 0.208 & $0.241^{*}$ \\
\hline & & & $(0.130)$ & $(0.134)$ \\
\hline & & Solicito & acteristics & \\
\hline \multirow[t]{2}{*}{ female solicitor } & & & & 0.080 \\
\hline & & & & $(0.131)$ \\
\hline \multirow[t]{2}{*}{ sociability } & & & & 0.008 \\
\hline & & & & $(0.026)$ \\
\hline \multirow[t]{2}{*}{ assertiveness } & & & & 0.021 \\
\hline & & & & $(0.020)$ \\
\hline \multirow[t]{2}{*}{ self efficacy } & & & & 0.010 \\
\hline & & & & $(0.029)$ \\
\hline \multirow[t]{2}{*}{ performance motivation } & & & & -0.042 \\
\hline & & & & $(0.032)$ \\
\hline \multirow[t]{2}{*}{ self confidence } & & & & -0.018 \\
\hline & & & & $(0.033)$ \\
\hline \multirow[t]{2}{*}{ BMI } & & & & -0.010 \\
\hline & & & & $(0.029)$ \\
\hline \multirow[t]{2}{*}{ solicitor beauty rating } & & & & 0.003 \\
\hline & & & & $(0.105)$ \\
\hline \multirow[t]{2}{*}{ constant } & $2.012 * * *$ & $2.267 * * *$ & $2.236 * * *$ & $2.393 * * *$ \\
\hline & $(0.149)$ & $(0.165)$ & $(0.179)$ & $(0.704)$ \\
\hline \multicolumn{5}{|l|}{ probability $F$ test } \\
\hline neighborhood effects & - & 0.009 & 0.006 & 0.021 \\
\hline respondent char. & - & - & 0.000 & 0.000 \\
\hline solicitor char. & - & - & - & 0.453 \\
\hline loglikelihood & -6629 & -6623 & -6613 & -6611 \\
\hline$R^{2}$ & 0.003 & 0.007 & 0.014 & 0.016 \\
\hline neighborhood fixed eff. & $\mathrm{NO}$ & YES & YES & YES \\
\hline observations & 2870 & 2870 & 2870 & 2870 \\
\hline \multicolumn{5}{|c|}{$\begin{array}{l}\text { Notes. Columns give estimated coefficients for distinct specifications of (2). The sample consists of al } \\
\text { households that opened the door. Standard errors are in parentheses. Errors are clustered at the solicitor level } \\
\mathrm{VCM}_{\text {Ano }} \text { is the benchmark and age between } 30 \text { and } 45 \text { is the default. Controls for missing gender information } \\
\text { are included in (3) and (4). 'Semidetached' is a dummy equal to one if the house is (semi-)detached. Solicito } \\
\text { personality traits are as in Rosenberg (1965); see also Soetevent }(2011) \text {. } 28 \text { observations of respondents unde } \\
\text { the age of } 14 \text { years have been dropped. A } F \text { test does not reject the null that the treatment coefficients ar } \\
\text { equal across the four specifications. } * * *(* * / *) \text { denotes significance at the } 1 \%(5 \% / 10 \%) \text { level. }\end{array}$} \\
\hline
\end{tabular}


Table 6: Probit regressions: Household participation decision

\begin{tabular}{|c|c|c|c|c|}
\hline Dependent variable & $\begin{array}{c}(1) \\
\text { donate }\end{array}$ & $\begin{array}{c}(2) \\
\text { donate }\end{array}$ & $\begin{array}{c}\text { (3) } \\
\text { donate }\end{array}$ & $\begin{array}{c}(4) \\
\text { donate }\end{array}$ \\
\hline & \multicolumn{4}{|c|}{ Treatment } \\
\hline \multirow{2}{*}{$\mathrm{VCM}_{\text {Add }}$} & -0.005 & -0.006 & -0.010 & -0.013 \\
\hline & $(0.0340)$ & $(0.040)$ & $(0.039)$ & $(0.041)$ \\
\hline \multirow[t]{2}{*}{ Lottery (LOT) } & -0.039 & -0.040 & -0.042 & -0.047 \\
\hline & $(0.041)$ & $(0.042)$ & $(0.041)$ & $(0.040)$ \\
\hline \multirow{2}{*}{ AllPay (APA) } & $-0.132 * * *$ & $-0.133 * * *$ & $-0.134 * * *$ & $-0.158 * * *$ \\
\hline & $(0.047)$ & $(0.047)$ & $(0.047)$ & $(0.040)$ \\
\hline \multicolumn{5}{|c|}{ Respondent characteristics } \\
\hline \multirow{2}{*}{ aged $<30$} & & & $-0.072 * *$ & $-0.074 * *$ \\
\hline & & & $(0.032)$ & $(0.032)$ \\
\hline \multirow[t]{2}{*}{ aged $45-60$} & & & $-0.081 * * *$ & $-0.079 * * *$ \\
\hline & & & $(0.023)$ & $(0.023)$ \\
\hline \multirow[t]{2}{*}{ aged $>60$} & & & $-0.077 * * *$ & $-0.079 * * *$ \\
\hline & & & $(0.028)$ & $(0.028)$ \\
\hline \multirow[t]{2}{*}{ female respondent } & & & $0.057 * * *$ & $0.058 * * *$ \\
\hline & & & $(0.017)$ & $(0.016)$ \\
\hline \multirow[t]{2}{*}{ semidetached } & & & 0.038 & 0.048 \\
\hline & & & $(0.036)$ & $(0.031)$ \\
\hline & & Solicito & acteristics & \\
\hline female solicitor & & & & $\begin{array}{c}0.017 \\
(0.033)\end{array}$ \\
\hline \multirow[t]{2}{*}{ sociability } & & & & 0.011 \\
\hline & & & & $(0.007)$ \\
\hline \multirow[t]{2}{*}{ assertiveness } & & & & 0.001 \\
\hline & & & & $(0.006)$ \\
\hline \multirow{2}{*}{ self efficacy } & & & & 0.005 \\
\hline & & & & $(0.008)$ \\
\hline \multirow[t]{2}{*}{ performance motivation } & & & & -0.008 \\
\hline & & & & $(0.007)$ \\
\hline \multirow[t]{2}{*}{ self confidence } & & & & -0.007 \\
\hline & & & & $(0.007)$ \\
\hline \multirow[t]{2}{*}{ BMI } & & & & 0.001 \\
\hline & & & & $(0.006)$ \\
\hline \multirow[t]{2}{*}{ solicitor beauty rating } & & & & 0.022 \\
\hline & & & & $(0.023)$ \\
\hline \multicolumn{5}{|l|}{ Probability $F$ test } \\
\hline neighborhood effects & - & 0.615 & 0.459 & 0.517 \\
\hline respondent char & - & - & 0.000 & 0.000 \\
\hline solicitor char. & - & - & - & 0.349 \\
\hline loglikelihood & -1885 & -1884 & -1868 & -1864 \\
\hline pseudo $R^{2}$ & 0.0093 & 0.0098 & 0.0183 & 0.0205 \\
\hline neighborhood fixed eff. & $\mathrm{NO}$ & YES & YES & YES \\
\hline observations & 2870 & 2870 & 2870 & 2870 \\
\hline \multicolumn{5}{|c|}{$\begin{array}{l}\text { Notes. Columns give estimated marginal effects (for variables denoted in the first column) for distinct } \\
\text { specifications of eq. (3). The sample consists of all households that opened the door when the solicitor rang. } \\
\text { Standard errors are in parentheses. Errors are clustered at the solicitor level. The anonymous VCM is the } \\
\text { benchmark treatment and age between } 30 \text { and } 45 \text { is default value. Controls for missing gender information are } \\
\text { included in columns (3) and (4). 'Semidetached' is a dummy variable with value equal to one if the respondent's } \\
\text { house is detached or semidetached. Solicitor personality traits are determined as in Rosenberg (1965); see also } \\
\text { Soetevent }(2011) \text {. } 28 \text { observations of respondents under the age of } 14 \text { years have been dropped from the } \\
\text { regressions. A } F \text { test does reject the null that the treatment coefficients shown in the table are equal for all four } \\
\text { specifications at the } 1 \% \text { level. } * * * * * / *) \text { denotes significance at the } 1 \%(5 \% / 10 \%) \text { level. }\end{array}$} \\
\hline
\end{tabular}


Coefficients to be estimated. Marginal effects estimates for different specifications of this model are presented in Table 6 .

In Tables 5 and 6, the first specification only includes treatment dummies. Neighborhood fixed effects are added in the second specification. Respondent characteristics are next included in model (3). Finally, specification (4) adds the set of solicitor characteristics.

In line with the preliminary findings in Table 4, the estimates in Tables 5 and 6 show that average contributions in APA by respondents who opened the door are $€ 0.32-€ 0.42$ lower than in the $\mathrm{VCM}_{\text {Ano }}$ treatment and that this lower level is mainly driven by the 13-16 percentage points lower participation rate in the APA. The latter result is very significant. In Table 5, we also find evidence that respondents under the age of 30 give significantly less and that female respondentsand respondents who live in detached or semidetached houses donate more. The latter result is only weakly significant (at the 10\%-level), but may proxy a wealth effect, because people in detached houses tend to be more wealthy than those living in a terraced house. In Table 6, we observe that all other age groups are significantly less likely to contribute than the benchmark group of 30-45 years old. Women are significantly more likely to contribute than men. $^{29}$

In contrast to previous door-to-door fundraising experiments (Landry et al., 2006; Soetevent, 2011), we do not observe an impact of solicitor personality traits or solicitor beauty rating on either contribution levels or participation decisions ( $p=0.453$ and 0.349 for the $F$ tests in tables 5 and 6 , respectively). ${ }^{30}$ To further explore where this difference with earlier studies comes from, we limit attention to the sample of donors (i.e. respondents who contribute a positive amount) and divide this in two subsamples: those donors who used the original envelope attached to the flyer received one week before the fundraising drive and those donors who used the replacement envelope given to them by the solicitor on the day of solicitation. Using the original envelope is likely to be positively correlated with having read the flyer and having prepared the donation in

\footnotetext{
${ }^{29}$ Regressions that include interaction terms between treatment dummies and respondents' age and gender, do not reveal any age specific treatment effects. The only significant result is that females are less likely to participate in APA than in either LOT or $\mathrm{VCM}_{\text {Add }}(p=0.040, F$ test $)$.

${ }^{30}$ Appendix $\mathrm{G}$ extends the specifications by interacting the gender of solicitors and respondents, by interacting beauty with the gender of the solicitor, by interacting the genders of the solicitor and respondent and by interacting beauty with treatment indicators. Inclusion of these terms does not have any impact on our results. The main additional finding is that female respondents give more generously, independent of the solicitor being a male or female. We find some evidence that physically attractive female solicitors induce a larger proportion of households to contribute but the estimated effect is smaller than in Landry et al.(2006)
} 
the envelope before the solicitor arrives. Respondents who use the replacement envelope are therefore more likely to base their decision on the information they receive from the solicitor about the charity and the fundraising procedure. Table 4 shows that, compared to the $\mathrm{VCM}_{\mathrm{Add}^{-}}$ treatment and conditional on donating, fewer donors use the original envelope in the LOT and APA treatments; the differences are significant ( $p=0.058$ and $p<0.001$, respectively). A possible explanation is that respondents in the relatively unknown APA and LOT environments are more likely to wait for an explanation by the solicitor before preparing a donation.

Table 7 shows the estimates of the linear regression model (2) for each of these subsamples. ${ }^{31}$ Since the samples are limited to donors, the estimates for treatment dummies should be interpreted as differences in the amount given (compared to $\mathrm{VCM}_{\mathrm{Ano}}$ ), conditional on donating a positive sum. The only significant treatment effect is for the VCM treatment with addresses when a replacement envelope is used: donors in this condition donate about $€ 0.50$ less than in the VCM treatment with blank envelopes. The $(10 \%)$ statistical significance of this effect disappears when we add solicitor effects, however. One explanation for such an effect is that respondents question why their address is on the envelope. Whereas the address serves a clear purpose in LOT and APA - it is used to identify the prize winner - the solicitor cannot offer a similarly obvious explanation in $\mathrm{VCM}_{\text {Ano }}$. This probably matters less when respondents read the flyer in advance and have had time to prepare their donation. ${ }^{32}$

There are not many other significant results in Table 7. Two significant findings warrant some discussion. First, the lower contributions among respondents under the age of 30 seem to be independent of the envelope used. Second, among the respondents who use a replacement envelope, those who live in (semi)detached houses tend to donate more. ${ }^{33}$ Two explanations are possible for this result. First, in a recent paper, DellaVigna et al. (forthcoming) provide empirical evidence that there is a social pressure cost of saying no to a solicitor. Arguably, this pressure is higher for respondents who have not prepared the envelope and receive additional explanation rom the solicitor, particularly if they live in a relatively luxurious dwelling. Alternatively, one may argue that this is the result of selection bias: among the donors living in a semidetached

\footnotetext{
${ }^{31}$ For completeness' sake, part $\mathrm{F}$ of the online appendix gives the results for the pooled data set (i.e., the differences with table 5 is that it explains contributions, conditional on donating a positive amount). The results are very much in line with those in table 7.

${ }^{32}$ The flyers for the two VCM treatments are identical, however. They do not give any explanation for the addressed envelopes.

${ }^{33}$ A Chow-test does however not reject the hypothesis that the coefficients in columns (5) and (6) are identical to those reported in columns (2) and (3), $p=0.237$ and $p=0.440$, respectively.
} 
Table 7: Household contributions, original vs. replacement envelope

\begin{tabular}{|c|c|c|c|c|c|c|}
\hline Dependent variable & $\begin{array}{c}(1) \\
\text { amount }\end{array}$ & $\begin{array}{c}(2) \\
\text { amount }\end{array}$ & $\begin{array}{c}\text { (3) } \\
\text { amount }\end{array}$ & $\begin{array}{c}\text { (4) } \\
\text { amount }\end{array}$ & $\begin{array}{c}(5) \\
\text { amount }\end{array}$ & $\begin{array}{c}\text { (6) } \\
\text { amount }\end{array}$ \\
\hline & \multicolumn{3}{|c|}{ ORIGINAL ENVELOPE } & \multicolumn{3}{|c|}{ REPLACEMENT ENVELOPE } \\
\hline \multirow{2}{*}{$\mathrm{VCM}_{\text {Add }}$} & -0.067 & -0.088 & -0.214 & $-0.489 *$ & $-0.523 *$ & -0.399 \\
\hline & $(0.222)$ & $(0.213)$ & $(0.206)$ & $(0.274)$ & $(0.262)$ & $(0.279)$ \\
\hline \multirow[t]{2}{*}{ Lottery (LOT) } & 0.235 & 0.172 & 0.164 & -0.249 & -0.288 & -0.225 \\
\hline & $(0.236)$ & $(0.218)$ & $(0.194)$ & $(0.196)$ & $(0.189)$ & $(0.179)$ \\
\hline \multirow{2}{*}{ AllPay (APA) } & 0.299 & 0.225 & 0.208 & 0.0765 & 0.0118 & 0.088 \\
\hline & $(0.256)$ & $(0.240)$ & $(0.234)$ & $(0.194)$ & $(0.178)$ & $(0.147)$ \\
\hline & \multicolumn{6}{|c|}{ Respondent Characteristics } \\
\hline \multirow{2}{*}{ aged $<30$} & & $-0.399 *$ & $-0.375^{*}$ & & $-0.372 *$ & $-0.344^{*}$ \\
\hline & & $(0.213)$ & $(0.217)$ & & $(0.194)$ & $(0.192)$ \\
\hline \multirow[t]{2}{*}{ aged $45-60$} & & 0.216 & 0.189 & & 0.175 & 0.178 \\
\hline & & $(0.170)$ & $(0.174)$ & & $(0.187)$ & $(0.183)$ \\
\hline \multirow[t]{2}{*}{ aged $>60$} & & -0.0333 & -0.049 & & -0.117 & -0.094 \\
\hline & & $(0.227)$ & $(0.218)$ & & $(0.217)$ & $(0.213)$ \\
\hline \multirow[t]{2}{*}{ female respondent } & & 0.178 & 0.172 & & 0.0878 & 0.091 \\
\hline & & $(0.180)$ & $(0.183)$ & & $(0.187)$ & $(0.190)$ \\
\hline \multirow[t]{2}{*}{ semidetached } & & 0.0206 & 0.045 & & $0.376^{*}$ & $0.363^{*}$ \\
\hline & & $(0.241)$ & $(0.257)$ & & $(0.197)$ & $(0.213)$ \\
\hline \multirow{3}{*}{ female solicitor } & \multicolumn{6}{|c|}{ Solicitor Characteristics } \\
\hline & & & -0.001 & & & 0.018 \\
\hline & & & $(0.153)$ & & & $(0.134)$ \\
\hline \multirow[t]{2}{*}{ sociability } & & & -0.047 & & & -0.053 \\
\hline & & & $(0.041)$ & & & $(0.042)$ \\
\hline \multirow[t]{2}{*}{ assertiveness } & & & 0.000 & & & $0.052 *$ \\
\hline & & & $(0.028)$ & & & $(0.027)$ \\
\hline \multirow{2}{*}{ self efficacy } & & & -0.036 & & & -0.006 \\
\hline & & & $(0.050)$ & & & $(0.045)$ \\
\hline \multirow[t]{2}{*}{ performance motivation } & & & -0.020 & & & -0.037 \\
\hline & & & $(0.050)$ & & & $(0.036)$ \\
\hline \multirow[t]{2}{*}{ self confidence } & & & -0.018 & & & 0.038 \\
\hline & & & $(0.057)$ & & & $(0.056)$ \\
\hline \multirow[t]{2}{*}{ BMI } & & & -0.001 & & & 0.016 \\
\hline & & & $(0.049)$ & & & $(0.052)$ \\
\hline \multirow[t]{2}{*}{ solicitor beauty rating } & & & -0.090 & & & -0.128 \\
\hline & & & $(0.174)$ & & & $(0.145)$ \\
\hline \multirow[t]{2}{*}{ constant } & $3.589 * * *$ & $3.530 * * *$ & $4.044 * * *$ & $3.297 * * *$ & $3.295 * * *$ & $2.900 * *$ \\
\hline & $(0.235)$ & $(0.216)$ & $(1.116)$ & $(0.145)$ & $(0.147)$ & $(1.110)$ \\
\hline \multicolumn{7}{|l|}{ probability $F$ test } \\
\hline neighborhood effects & 0.000 & 0.000 & 0.001 & 0.000 & 0.000 & 0.001 \\
\hline respondent char. & - & 0.059 & 0.058 & - & 0.026 & 0.062 \\
\hline solicitor char. & - & - & 0.223 & - & - & 0.710 \\
\hline loglikelihood & -2639 & -2636 & -2634 & -2404 & -2401 & -2399 \\
\hline$R^{2}$ & 0.018 & 0.023 & 0.027 & 0.012 & 0.019 & 0.022 \\
\hline neighborhood fixed eff. & YES & YES & YES & YES & YES & YES \\
\hline observations & 1090 & 1090 & 1090 & 997 & 997 & 997 \\
\hline $\begin{array}{l}\text { Notes. Columns give estimat } \\
\text { sample of respondents with } \\
\text { replacement envelopes. All } \\
\text { Standard errors are in parenth } \\
\text { is default. Controls for missir } \\
\text { the respondent's house is (se } \\
(2011) .28 \text { observations of res }\end{array}$ & $\begin{array}{l}\text { d coefficien } \\
\text { original env } \\
\mathrm{CM}_{\text {Ano obse }} \text { obs } \\
\text { ses. Errors } \\
\text { gender inf } \\
\text { ni-)detached } \\
\text { ondents unc }\end{array}$ & $\begin{array}{l}r \text { distinct } \mathrm{sp} \\
\mathrm{e} \text { in the } \mathrm{V} \\
\text { ions are inc } \\
\text { lustered at } \mathrm{t} \\
\text { tion are incl } \\
\text { licitor perso } \\
4 \text { have been }\end{array}$ & $\begin{array}{l}\text { ations of eq } \\
\text { dd, Lottery } \\
\text { because th } \\
\text { icitor level. } \\
\text { in }(2),(3),( \\
\text { traits are d } \\
\text { ed } * * *(* * / *\end{array}$ & $\begin{array}{l}\text { conditional } \\
\text { All-Pay tre } \\
\text { as only on } \\
\text { Ano is the b } \\
\text { d (6). 'Sem } \\
\text { ined as in I } \\
\text { otes signific }\end{array}$ & $\begin{array}{l}\text { pening the } \\
\text { t; (4)-(6) u } \\
\text { of envelor } \\
\text { lark and age } \\
\text { hed' is a du } \\
\text { berg }(1965) \\
\text { at the } 1 \%(5\end{array}$ & $\begin{array}{l}\text { 1)-(3) use } \\
\text { sample w } \\
\text { is treatme } \\
\text { en } 30 \text { and } \\
\text { qual to on } \\
\text { lso Soetev } \\
\text { level. }\end{array}$ \\
\hline
\end{tabular}


house, those who did not read the flyer presumably have the highest opportunity cost of time and have the financial means to a make a more generous donation.

One may expect solicitor personality traits to have a larger impact on the level of donations if the respondent has not prepared this donation beforehand (because $\mathrm{s} / \mathrm{he}$ has otherwise decided on the donation without interacting with the solicitor). Table 7 lends only very limited support to this hypothesis. The only personality trait that is identified to significantly (at the $10 \%$-level) increase conditional contributions is solicitor assertiveness. A one-point increase in solicitor assertiveness leads to an on average $€ 0.05$ increase in conditional donations when the donor needs a replacement envelope. The F-tests reported in table 7 also show no joint effect of solicitor characteristics, for either type of envelope. However, since the sample is (by its very nature) limited to donors only, we cannot determine the extent to which solicitor characteristics help to increase participation among respondents who have not prepared the original envelope.

All in all, we conclude that the effect of the solicitor on contributions that has been observed in previous studies is not replicated in our field setting. ${ }^{34}$ The main remaining effect is that solicitors in general do not succeed in explaining to unprepared respondents why an envelope in the VCM treatment is marked with their address.

\section{DISCUSSION}

We can now relate the empirical results to the hypotheses derived in Section 3 and discuss their implications. Our first hypothesis (average donation) predicts that the average donation per household is higher in the all-pay auction than in the lottery and higher in the lottery than in the VCM treatments. The results in Table 5 firmly reject this hypothesis. Highest contributions are observed in the anonymous VCM, which was predicted to show the lowest. Here, the all-pay auction (predicted to have highest contributions) even proves to have significantly lower donations than $\mathrm{VCM}_{\text {Ano }}$.

$\mathrm{H} 2$ (participation) predicts that more respondents will contribute in the all-pay auction and the lottery than in either VCM. This is once again clearly rejected by our results. In fact, participation is significantly lower in APA than in all other treatments. Differences between other treatments in participation are not statistically significant at the $10 \%$-level. This is

\footnotetext{
${ }^{34}$ One unexplored issue is whether the impact of solicitor personality traits varies systematically with treatment. The number of solicitors per treatment $(8,7,15,15)$ is too limited to allow a regression with treatment interacted with each of the seven characteristics, however.
} 
reminiscent of the result in Carpenter et al. (2008) that participation is lower in all-pay auctions than in alternative auction formats. Recall that Carpenter et al. compare other mechanisms than we do, however. Most importantly, their design does not include a lottery or VCM. Nevertheless, our results do support -with data from an entirely different context- their finding that participation is relatively low in the APA.

We therefore conclude that the predictions derived from the model usually applied to charity auctions (an equilibrium bidding model where preferences are augmented to include utility from giving) find no support in our data. Our data clearly reject the hypotheses that APA raises more than LOT, that both mechanisms raise more than VCM, and that the VCMs do not differ in terms of money raised. We discuss six potential explanations for these 'anomalies'.

\section{(i) Competition crowds out intrinsic motivations}

Bernasconi et al. (2010) show in a public goods game that obligations to contribute reduce voluntary contributions. This result follows from a long tradition of research on the relationship between intrinsic and extrinsic motivation (e.g., Kreps 1997, Frey 1997, Bowles 1998, Frey and Jegen 2001; Fuster and Meier 2010). This literature stresses how externally imposed rules and obligations (like those in Bernasconi et al.) may crowd out intrinsic, pro-social motivations. Of course, in our design, we do not formally impose obligations in any of the treatments. Subjects may have experienced this differently, however. The idea that there is a prize that one can compete for may make some people realize that we are appealing to other motivations than just the intrinsic pro-social feelings they may have. APA may have precisely this effect. In fact, some participants put angry notes in the envelope with their donations that strongly suggest that this effect may be driving some of our results (a translation of these notes is presented in appendix A.3) ${ }^{35}$ If APA does crowd out intrinsic motivations, this may be a cultural response. In this respect it would be interesting to replicate our design in other countries. ${ }^{36}$ Finally, crowding out may also be explained with the Bénabou and Tirole (2006) model of image motivation, where external rewards diminish the signal value of a contribution. This theory may explain the lower

\footnotetext{
${ }^{35}$ Moreover, aside from comments mentioning anonymity, many respondents said in more general terms that they disapproved of the set up. This type of comment was especially heard in APA: 60 times, against 22 in LOT, 5 in $\mathrm{VCM}_{\text {Add, }}$, and 0 in $\mathrm{VCM}_{\text {Ano. }}$.

${ }^{36}$ Moreover, the phenomenon of crowding out may depend on the type of prize. A seminar participant pointed out that non-scarce prizes like a Nintendo may cause more crowding out than a scarce prize like Eric Clapton's guitar. Because it seems almost impossible to collect large data sets for scarce prizes, this hypothesis is difficult to test.
} 
revenues in APA, but it does not offer a clear-cut explanation for the observed difference in performance between APA and LOT. LOT does much better in terms of participation despite the presence of an extrinsic reward that may dilute the signaling value of pro-social behavior.

\section{(ii) Objections to non-anonymity}

A considerable number of respondents explicitly indicated that they dislike the non-anonymous VCM, lottery and all-pay treatments. In $\mathrm{VCM}_{\text {Add }} 19$ people indicated (either to the solicitor or by putting a note in the envelope) that they had problems with their address on the envelope. In LOT and APA, this number is lower, with 12, resp. 16 respondents (on a sample that is about twice as large). We do note that some of these people donated despite their complaints. Further, non-anonymity may be related to the crowding out effect discussed in (i). For example, the effectiveness of extrinsic motives decreases with the visibility of a social act (Ariely et al. 2009). Note that this negative effect of non-anonymity contradicts the idea that public recognition enhances charitable donations (Karlan and McConnell 2009).

\section{(iii) Low-cost signaling}

The optimal bid functions for the all-pay auction are hockey-stick shaped functions of the value of the prize (Goeree et al. 2005, Schram and Onderstal 2009). For most distributions of values, this means that there will be many people whose equilibrium bid is very low (as are, therefore, their chances of winning the item). Therefore, the opportunity costs of bidding (contributing) zero (i.e., not participating) are very low. There are, then, many reasons why people may indeed refrain from contributing, ranging from the mental costs of deciding how much to give to the physical costs of having to get the money. Because such reasons would also hold for contributions in the VCM (where we observed higher participation), we prefer one that is related to point (i). If participants morally object to the idea that a prize is linked to charitable giving, the costs of expressing this objection by not contributing are for most people very low. In figure 1, this shows up in the peak at zero and lower fractions in APA of contributions of relatively low amounts. 


\section{(iv) Asymmetric values}

The revenue ranking of APA and LOT and the lower participation in APA than in LOT are in line with Bos' (2011) equilibrium analysis of both mechanisms. In a setting with complete information, he shows that LOT may raise more money than APA if donors are sufficiently asymmetric, specifically, if the values of the donors with the highest two values are sufficiently different. Moreover, he finds that in equilibrium, participation is much lower in APA than in LOT. While Bos derives his results in the extreme case of complete information they may still be indicative as to why our data do not support our hypotheses with respect to APA and LOT. Indeed, donors may be asymmetric in terms of how they value a Nintendo DS with Dr. Kawashima's Brain Training Pack. Moreover, donors may have at least some idea about how others value the prize. For example, it may be common knowledge that families with children or a neighbor who has suffered from brain damage are likely to be willing to pay much more for the prize than the average donor. Therefore, potential donors with low values may decide to donate little if anything in APA because they believe that they have little chance of winning because they will definitely be outbid by someone with a more serious interest in the prize. In LOT, they may decide to donate more because they still have a reasonable chance of winning. Note that this approach cannot explain distinct contribution levels between on the one hand LOT or APA and on the other hand the VCMs. Finally, one possible cause of asymmetric values may be age. Perhaps young respondents value the Nintendo more highly than older respondents. They may then contribute less in the VCMs and more in the prize treatments. Appendix H addresses this question in two different ways and concludes that there is no such interaction effect between age and treatment.

\section{(v) Asymmetric barriers to participation}

Carpenter et al. (2010) provide a theoretical model in an attempt to explain why participation in the all-pay auctions observed in their previous experiment (2008) was lower than in the other auction formats. They show that endogenous participation and participation costs alone "cannot explain the underperformance of the all-pay mechanism in the Carpenter et al. (2008) field experiment", and argue that there must be asymmetric barriers to participation to explain observed differences. They then go on to discuss various possible asymmetries. This would be a possible explanation for our results as well. For our treatments, it is not clear why such barriers 
would be asymmetric, however. For example, in our framing of the lottery and all-pay auctions, there is no reason to consider the all-pay auction more difficult to understand. If anything, it seems easier to understand that the highest contribution wins than that the probability of winning is monotonically increasing in the contribution. In absence of clear reasons for differences across treatments, a theory of asymmetric barriers says no more than that people will participate less in some treatments because there are higher barriers to participation.

\section{(vi) Decreasing marginal altruism.}

Goeree et al. (2005) show that under the assumption of proportional benefits from the own contribution, APA generates higher expected equilibrium revenue than LOT. In other words, if $B_{A P A}$ and $B_{L O T}$ are the equilibrium contribution functions for APA and LOT respectively, it holds that

$$
E\left\{B_{A P A}(v)\right\}>E\left\{B_{L O T}(v)\right\}
$$

because the charity's revenue is a donor's expected contribution times the number of donors. By relaxing the assumption of proportional benefits from the own contribution, the revenue ranking of APA and LOT may be reversed. Suppose, for instance, that $\omega(d)=d-g(d)$ where $g$ is a differentiable, strictly increasing and convex function with $g(0)=0$ and $g^{\prime}(d)<1$. This model can be interpreted as the standard model where bidders pay the auctioneer $d-c(d)=g(d)$ instead of $d$. Therefore, the equilibrium donation can be derived equating the "net utility loss from donating' to the equilibrium donation in the standard model. More precisely, if donor $i$ donates $b_{i}$ in equilibrium in the standard model, her equilibrium donation $d_{i}$ follows by solving $d_{i}-\omega\left(d_{i}\right)=$ $g\left(d_{i}\right)=b_{i}$ or $d_{i}=g^{-1}\left(b_{i}\right)$.

For the standard model, a closed-form solution does not exist for the equilibrium of LOT. For this reason, Schram and Onderstal (2009) rely on a numerical approximation of the equilibrium for a setting with three bidders and a uniform value distribution. They observe that for values below some threshold value, donors donate more in LOT than in APA, while the reverse is true for values above this threshold. Given those properties of the equilibrium bidding function, a function $g$ exists for which 


$$
E\left\{g^{-1}\left(B_{A P A}(v)\right)\right\}<E\left\{g^{-1}\left(B_{L O T}(v)\right)\right\}
$$

i.e., for which APA raises less than LOT. A strongly convex $g$ suffices, which corresponds to a strongly concave utility from donating in (5), i.e., where a donor has a strongly decreasing marginal utility from donating. Once again note that this cannot explain the differences between either lottery or all-pay and the VCM treatments. Moreover, this line of reasoning cannot explain differences in participation.

\section{CONCLUDING REMARKS}

One important conclusion from our field experiment is that an anonymous VCM raises more money than any of the other mechanisms studied, including a lottery and an all-pay auction. This is remarkable for at least two reasons. First, it is hard to come up with (standard) economic theory that would predict this result. Second, it is the mechanism predominantly used by charities in door-to-door fundraising in the Netherlands. In analyzing the reasons for this result, we favor the explanation that describes how intrinsic, pro-social motivations may be crowded out by the possibility of winning a prize, especially when it is relatively cheap to express disapproval of the setup. Two observations in support of this explanation are (i) the angry notes we received from some participants (as described above); and (ii) in a debriefing meeting with the charity concerned, this point was readily recognized. Importantly, the fact that crowding out takes place is unlikely to be attributable to unfamiliarity with prize winning mechanisms. Lotteries and auctions are common ways to raise money for Dutch charities that do not raise funds door-todoor and are occasionally used in door-to-door fundraising drives.

In some ways, it may seem disconcerting that the results from the theoretical analysis, laboratory and field experiments diverge. On the other hand, our results also diverge from the Landry et al. (2006) field experiment where higher revenues are observed in LOT than in VCM. This difference may be due to their use of a common value prize, to cultural differences between the U.S. (where their study was conducted) and the Netherlands, or to many other differences between the two studies. ${ }^{37}$ This simply shows that the external validity of any single field

\footnotetext{
${ }^{37}$ The difference in prize salience may also explain why our results differ from Landry et al.'s (2006). In their single-prize lottery treatment, they allocated a $\$ 1000$ prize for a total of 363 households home, while we let about 200 households answering the door compete for prizes with shop value $€ 169$. Even if the loss in intrinsic motivation
} 
experiment is limited. More informative is a complete package of theory, laboratory research and field experiments, i.e., a complete overview as presented in Table 1. That is what our study aims to contribute to.

is the same in both settings, households in their experiment may have been compensated by the larger extrinsic motivation to donate. 


\section{APPENDIX}

\section{A.1 Flyers}

Here we provide a translation of the flyers distributed a week before the solicitors walked their routes. There were three such flyers: one for both VCMs, one for LOT and one for APA. All flyers carried the logo of the University of Amsterdam as well as that of the Brain Research Foundation and the Central Bureau of Fundraising (CBF).

\section{VCMs}

\section{Give to the solicitor}

Contribute to the Brain Research Foundation's good work! A solicitor for the Brain Research Foundation will visit you between February 1 and 6.

This year's collection in your neighborhood may be different than what you are used to. This collection is part of a research project by the University of Amsterdam on households' charitable giving.

We kindly request that you prepare your contribution by putting it in the attached envelope and keeping this near your front door.

We understand that you may have questions. If so, please contact the University of Amsterdam (telephone number given) or the Brain Research Foundation (telephone number given). 


\section{Lottery}

\section{Give to the solicitor (and win!)}

Contribute to the Brain Research Foundation's good work! A solicitor for the Brain Research Foundation will visit you between February 1 and 6.

This year's collection in your neighborhood may be different than what you are used to. This collection is part of a research project by the University of Amsterdam on households' charitable giving. For this purpose, the university has provided a Nintendo DS game computer with Dr. Kawashima's Brain Training. A lottery amongst 300 households in your neighborhood will determine who gets this prize. You and every other contributor will receive for each euro one (virtual) ticket. One of the tickets will be randomly chosen and its holder wins the brain trainer.* The solicitor will approach each house only once.

We kindly request that you prepare your contribution by putting it in the attached envelope and keeping this near your front door.

We understand that you may have questions. If so, please contact the University of Amsterdam (telephone number given) or the Brain Research Foundation (telephone number given).

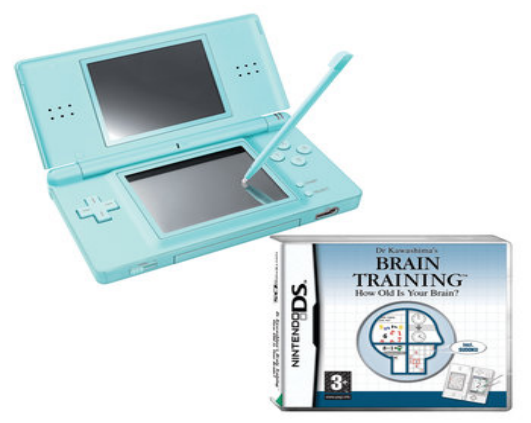

* If the contributed amount is not a round number, the donator will receive the corresponding part of a ticket. A contribution of $€ 1.40$ gives $1+4 / 10$ th of a ticket. If the $4 / 10$ th is drawn, the owner also wins the brain trainer. The chance of winning is only $40 \%$ of the chance of winning with a whole ticket, however.

Winners will be notified in the week starting March 1st. It is not possible to receive the value of the prize in cash. No legal rights may be inferred from the picture of the prize. The lottery is conducted by permission of the municipality of Amstelveen, permit VO2009-13559-eb granted 07-12-2009. 


\section{All Pay}

\section{Give to the solicitor (and win!)}

Contribute to the Brain Research Foundation's good work! A solicitor for the Brain Research Foundation will visit you between February 1 and 6.

This year's collection in your neighborhood may be different than what you are used to. This collection is part of a research project by the University of Amsterdam on households' charitable giving. For this purpose, the university has provided a Nintendo DS game computer with Dr. Kawashima's Brain Training. 300 households in your neighborhood compete for this prize. For this purpose, the university will compare the contributions of all of these households. The household that contributes most will win the brain trainer.* The solicitor will approach each house only once.

We kindly request that you prepare your contribution by putting it in the attached envelope and keeping this near your front door.

We understand that you may have questions. If so, please contact the University of Amsterdam (telephone number given) or the Brain Research Foundation (telephone number given).

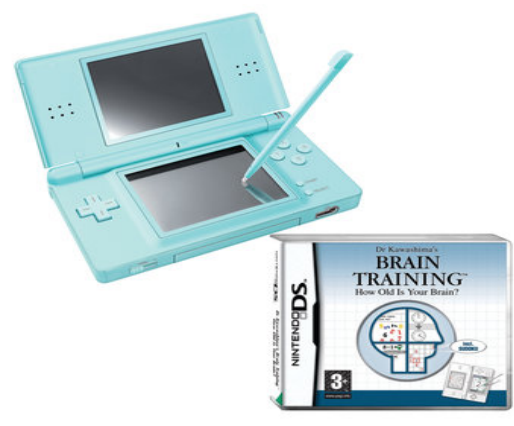

\footnotetext{
* If two or more households contribute most, the prize will be randomly allocated to one of these. For example, if
} two households have contributed the highest amount, each will win the prize with probability $50 \%$,

Winners will be notified in the week starting March 1st. It is not possible to receive the value of the prize in cash. No legal rights may be inferred from the picture of the prize. 


\section{A.2. Proof of Proposition 1}

In equilibrium, donor $i$ maximizes her expected utility, which is given by

$$
U_{i}=\pi_{i} u_{i}\left(w_{i}+v_{i}-d_{i}\right)+\left(1-\pi_{i}\right) u_{i}\left(w_{i}-d_{i}\right)+\omega_{i}\left(d_{i}\right)+\delta_{i}\left(D_{-i}\right)
$$

where $\pi_{i}$ represents the probability of donor $i$ winning the prize. Note that for both APA and LOT, $\pi_{i}$ is weakly increasing in donor $i$ 's contribution and weakly decreasing in the contributions of other donors. The equilibrium donation by donor $i$ can be found by maximizing (7) with respect to $d_{i} \in\left[0, c_{i}\right]$. Observe that

$$
\frac{\partial U_{i}}{\partial d_{i}}=\frac{\partial \pi_{i}}{\partial d_{i}}\left[u_{i}\left(w_{i}+v_{i}-d_{i}\right)-u_{i}\left(w_{i}-d_{i}\right)\right]-\pi_{i} u_{i}^{\prime}\left(w_{i}+v_{i}-d_{i}\right)-\left(1-\pi_{i}\right) u_{i}^{\prime}\left(w_{i}-d_{i}\right)+\omega_{i}^{\prime}\left(d_{i}\right) .
$$

In both VCMs, $\pi_{i}=0$. Therefore, for the optimal donation $d_{i}^{V C M}$, it holds that

$$
\omega_{i}^{\prime}\left(d_{i}^{V C M}\right) \geq u_{i}^{\prime}\left(w_{i}-d_{i}^{V C M}\right)
$$

unless $\omega_{i}^{\prime}(0)<u_{i}^{\prime}(0)$. In this case, $d_{i} V C M=0$ so that donor $i$ donates at least as much in APA and LOT than in the VCMs. Substituting (9) into (8) yields

$$
\frac{\partial U_{i}}{\partial d_{i}} \geq \frac{\partial \pi_{i}}{\partial d_{i}}\left[u_{i}\left(w_{i}+v_{i}-d_{i}^{V C M}\right)-u_{i}\left(w_{i}-d_{i}^{V C M}\right)\right]-\pi_{i}\left[u_{i}^{\prime}\left(w_{i}+v_{i}-d_{i}^{V C M}\right)-u_{i}^{\prime}\left(w_{i}-d_{i}^{V C M}\right)\right] \geq 0
$$

The second inequality follows because $\pi_{i}$ is weakly increasing in $d_{i}, u_{i}$ is strictly increasing and $u_{i}{ }^{\prime}$ is weakly decreasing (as $u_{i}$ is concave). So, donor $i$ 's utility is increasing at the point $d_{i}=$ $d_{i}{ }^{V C M}$. Therefore, her equilibrium donation in both APA and LOT is at least as high as her donation in both VCMs. 


\section{A.3. Some written comments by donors}

\section{All-pay auction}

"Giving a prize to the most generous donator in this way is absolutely unacceptable for me.

Therefore, as a matter of principle I will not give anything now."

"We do not think that a charity contest is a good idea"

"We find this way of fundraising unacceptable. Therefore, we will not participate.

"Too bad. We do not want to donate like this. Missed 'opportunity'."

"I will not participate in this way."

"We do not want a prize or a reward."

"We already donate $€ 5$ per month, so $€ 60$ per year. Count that too. Good luck."

"This campaign [...] has caused me (and others) resentment. The reason is that $[\ldots]$ it could push the less well-to-do 'off the market'. We do not think this will benefit the charity"

"Too bad. In my opinion, the fundraisers must have damaged their brain when designing this campaign."

\section{Lottery}

"This is an unfair way of raising money. Sorry."

\section{VCM $_{\text {Ano }}$}

"We donate by bank transfer!"

"My way of charitable giving? I donate to about 12 charities. That suffices."

\section{$\mathrm{VCM}_{\text {Add }}$}

"We disagree that researchers use data on our donation (without first asking us)!"

"In our opinion this is impertinent and therefore a reason not to donate."

"It is nobody's business how much I would donate!"

"We support about 25 different charities, almost all by automatic bank transfers. Door-to-door fundraisers do not give a good picture of our "household's charitable giving". This suggestion is misleading." 


\section{REFERENCES}

Andreoni, J. "Warm-glow versus Cold-prickle: The Effects of Positive and Negative Framing on Cooperation in Experiments." Quarterly Journal of Economics 110 (1995) : 1-21.

Andreoni, J. and R. Petrie. "Public Goods Experiments Without Confidentiality: A Glimpse into Fund-Raising.” Journal of Public Economics 88 (2004), 1605-1623.

Ariely, D., A. Bracha and S. Meier. "Doing Good or Doing Well? Image Motivation and Monetary Incentives in Behaving Prosocially.” American Economic Review 99 (2009), $544-555$.

Bénabou, R. and J. Tirole. "Incentives and Prosocial Behavior." American Economic Review 96 (2006), 1652-1678.

Bernasconi, M, L. Corazzini and L, A. Marenzi. "Expressive Obligations in Public Good Games: Crowding-in and Crowding-out Effects.” Working Papers 2010 04, University of Venice “Ca' Foscari”, Department of Economics (2010).

Bohnet, Iris and Bruno Frey. "Social Distance and Other-Regarding Behavior in Dictator Games:

Comment.” American Economic Review 89 (1999), 335-339.

Bos, O. “How Lotteries Outperform Auctions.” Economics Letters 110 (2011), 262-264.

Bowles, S. "Endogenous Preferences: The Cultural Consequences of Markets and Other Economic Institutions.” Journal of Economic Literature 36 (1998), 75-111.

Bracha, A., M. Menietti and L. Vesterlund. "Seeds to Succeed? Sequential Giving to Public Projects.” Journal of Public Economics 95 (2011), 416-427.

Carpenter, J., J. Holmes and P.H. Matthews. “Charity Auctions: A Field Experiment.” Economic Journal 118 (2008), 92-113.

Carpenter, J., J. Holmes and P.H. Matthews. "Endogenous Participation in Charity Auctions." Journal of Public Economics 94 (2010), 921-935.

Carpenter, J., J. Holmes and P.H. Matthews. "An Introduction to "Bucket Auctions" for Charity.” Mimeo, Middlebury College (2011).

CBF, "Verslag Fondsenwerving 2009" (2009).

Corazzini, L., M. Faravelli and L. Stanca. "A Prize to Give for: An Experiment on Public Good Funding Mechanisms.” Economic Journal 120 (2010), 944-967.

Croson, R. and J. Shang. "The impact of downward social information on contribution decisions." Experimental Economics 11 (2008), 221-233. 
DellaVigna, S., J.A. List and U. Malmendier. "Testing for Altruism and Social Pressure in Charitable Giving." Quarterly Journal of Economics_(forthcoming).

Faravelli, M. "The Important Thing is Not (Always) Winning but Taking Part: Funding Public Goods with Contests." Journal of Public Economic Theory 13 (2011), 1-22.

Frey, B.S. Not Just for the Money: An Economic Theory of Personal Motivation. (1997)

Edward Elgar, Cheltenham.

Frey, B.S. and R. Jegen. "Motivation Crowding Theory: A Survey of Empirical Evidence." Journal of Economic Surveys 15 (2001), 589-611.

Frey, B. S. and S. Meier. "Social Comparisons and Pro-social Behavior: Testing "Conditional Cooperation" in a Field Experiment.” American Economic Review 94 (2005), 17171722 .

Fuster, A. and S. Meier. “Another Hidden Cost of Incentives: The Detrimental Effect on Norm Enforcement." Management Science 54 (2010), 57-70.

Goeree, J.K., E. Maasland, S. Onderstal and J.L. Turner. "How (Not) to Raise Money.” Journal of Political Economy 113 (2005), 897-918.

Harrison, G.W. and J.A. List. "Field Experiments." Journal of Economic Literature 42 (2004) $1009-1055$.

Isaac, R.M. and K. Schnier. "Silent Auctions in the Field and in the Laboratory." Economic Inquiry 43 (2005), 715-733.

Isaac, R.M., S. Pevnitskaya and T. Salmon. "Do Preferences for Charitable Giving Help Auctioneers?." Experimental Economics, 13 (2010), 14-44.

Isaac, R.M. and T. Salmon. "Revenue from the Saints, the Showoffs, and the Predators: Comparisons of Auctions with Price-Preference Values." Research in Experimental Economics 11, by D.D. Davis and R.M. Isaac (Eds.), JAI (Elsevier Science) (2006): 130 .

Karlan, D. and M.A. McConnell. "Hey Look at Me: The Effect of Giving Circles on Giving". Working paper, Yale University (2009).

Kreps, D. M. "Intrinsic Motivation and Extrinsic Incentives." The American Economic Review 87 (1997), 359-364.

Kumru, C. S. and L. Vesterlund. "The Effect of Status on Charitable Giving." Journal of Public Economic Theory 12 (2010), 709-735. 
Landry, C., A. Lange, J.A. List, M.K. Price and N.G. Rupp. "Towards an Understanding of the Economics of Charity: Evidence from a Field Experiment." Quarterly Journal of Economics 121 (2006), 747-782.

Lange, A., J.A. List and M.K. Price. "Using Lotteries to Finance Public Goods: Theory and Experimental Evidence.” International Economic Review 48 (2007), 901-927.

Morgan, J. "Financing Public Goods by Means of Lotteries." Review of Economic Studies 67 (2000), 761-784.

Morgan, J. and M. Sefton. "Funding Public Goods with Lotteries: Experimental Evidence." Review of Economic Studies 67 (2000), 785-810.

Myerson, R.B. "Optimal Auction Design.” Mathematics of Operations Research 6 (1981), 5873.

Potters, J., M. Sefton and L. Vesterlund. "After You - Endogenous Sequencing in Voluntary Contribution Games.” Journal of Public Economics 89 (2005), 1399-1419.

Orzen, H. "Fundraising through Competition: Evidence from the Lab." CeDEx working paper 2008-11 (2008).

Patel, A., E. Cartwright and M. van Vugt. "Punishment Cannot Sustain Cooperation in a Public Good Game with Free-Rider Anonymity.” Working Papers in Economics 451, Göteborg University, Department of Economics (2010).

Rege, M. and K. Telle. "The Impact of Social Approval and Framing on Cooperation in Public Good Situations.” Journal of Public Economics 88, (2004) 1625-1644.

Rosenberg, M. Society and the Adolescent Self-Image. Princeton University Press (1965).

Schram, A.J.H.C. and S. Onderstal. "Bidding to Give: An Experimental Comparison of Auctions for Charity." International Economic Review 50 (2009), 431-457.

Soetevent, A.R. "Anonymity in Giving in a Natural Context, A Field Experiment in 30 Churches.” Journal of Public Economics 89 (2006), 2301-2323.

Soetevent, A.R. "Payment Choice, Image Motivation and Contributions to Charity: Evidence from a Field Experiment.” American Economic Journal: Economic Policy 3 (2011), 180 205. 